\title{
Property Rights, Extortion and the Misallocation of Talent*
}

\author{
Ashantha Ranasinghe ${ }^{\dagger}$ \\ University of Toronto
}

December 2011

\begin{abstract}
How do institutions affect resource misallocation? This paper focuses on a particular class of institutions, namely property rights, and their relation to extortion. Motivated by empirical evidence that there are differences in extortion rates across establishments, both within and across countries, I examine whether extortion is an important channel for understanding resource misallocation. I construct a model in which agents choose between entrepreneurship and working, and where a criminal group can extort entrepreneur capital. While property rights are common across agents, extortion rates arise endogenously as an inverted ' $u$ ' shape in agent's ability. In economies characterized by weak property rights, extortion is prevalent and resource misallocation can generate TFP and output losses of 10 and 30 percent. TFP and output losses arise from two channels: selection and misallocation. Extortion affects selection by altering the ability threshold required for entry into entrepreneurship, while misallocation occurs because entrepreneurs operate below the optimal scale. As property rights decrease, extortion rates are higher and TFP and output losses from selection and misallocation are magnified.
\end{abstract}

JEL: 01, 04

Key Words: extortion, misallocation, TFP, property rights.

*An up to date version of the paper can be found at https://sites.google.com/site/ashanthar.

${ }^{\dagger}$ I thank Diego Restuccia, Margarida Duarte and Gueorgui Kambourov. I have also received valuable feedback from Branko Boskovic, Pedro Bento, Gustavo Bobonis, Elton Dusha, Sacha Kapoor, Burhan Kuruscu, Josh Lewis, Rob McMillan, Angelo Melino, Peter Morrow, Shouyong Shi, Trevor Tombe and participants at the CEPA and Macro Seminar at the University of Toronto. Correspondence: a.ranasinghe@utoronto.ca 


\section{Introduction}

A large literature has emphasised that resource misallocation is an important channel for understanding TFP differences across countries. A central theme is that resource misallocation is especially large when distortions are idiosyncratic across establishments. ${ }^{1}$ While the literature has examined how specific policies can have idiosyncratic effects across establishments much less attention has been devoted to the role that institutions can have in creating and perpetuating distortions that are idiosyncratic across establishments. This paper focuses on a particular class of institutions, namely property rights, their relation to extortion, and its impact on TFP and aggregate output through resource misallocation. Though uncommon in the western world, empirical evidence suggests that extortion is a major hindrance for establishments in developing economies. ${ }^{2}$ As shown in Table 1, extortion payments are an obstacle for doing business, occurs frequently and varies in magnitude across establishments. For example, some establishments do not face extortion while for others extortion payments can be about 15 percent of their annual sales. Moreover, there is variation in average extortion payments across countries and these payments are inversely related with property rights (see Figure 1). Given the variation in extortion payments, both across and within countries, how important is extortion for understanding resource misallocation and in turn TFP and output losses? In economies characterized by weak property rights, I find that extortion can generate significant resource misallocation leading to output and TFP losses that can be upwards of 30 and 10 percent, respectively.

To see why output and TFP losses can be substantial, consider an environment in which agents choose between becoming an entrepreneur and a worker, and in which a criminal group (CG) can extort the proceeds from entrepreneur production. ${ }^{3}$ Suppose property rights are perfect and there is no opportunity for a CG to extort from entrepreneurs. Then only the most productive agents become entrepreneurs and production is at optimal capacity, yielding the first-best outcome. Now consider the case when property rights are no longer perfect and where the CG has an opportunity to extort a share of the proceeds from entrepreneur production. Output and TFP losses can arise from two potential sources: selection and misallocation.

\footnotetext{
${ }^{1}$ See for example Restuccia and Rogerson (2008) and Hsieh and Klenow (2009).

${ }^{2}$ I define extortion as "...a racket in which a local strong man forces merchants to pay tribute in order to avoid damage - damage the strong man himself threatens to deliver" (Charles Tilly, 1985). For papers related to extortion see Gambetta (1996, 2000), Lotspeich (1997) and Volkov (1999).

${ }^{3}$ Typically the mafia or criminal organization approaches the potential victim (entrepreneur) and demands a payment, where failure to comply can result in physical harm or damage to property. I refer to such payments as extortion. How successful and the magnitude of the extortion fee depend on the property rights (for example policing) and the ability of the victim to pay the fee.
} 


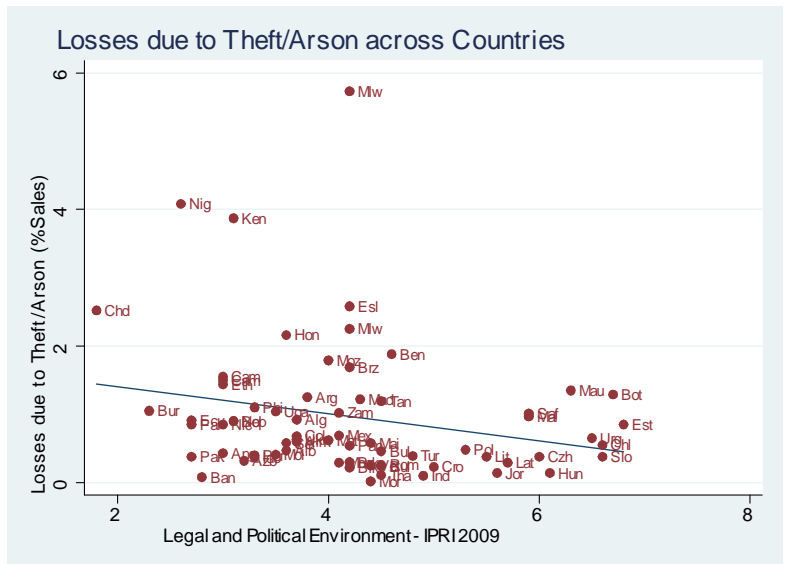

Figure 1: This figure plots cross country average losses due to theft, arson and robbery, as a percentage of establishment sales, against a measure of property rights reported in the IPRI 2009. For country level averages, I use 'losses due to theft, arson and robbery', as provided by the World Bank Enterprise Survey, as a proxy for extortion ( see Appendix for the correlation). While extortion data is available at the establishment level, country level averages are not. Country level averages and establishment level data for theft/robbery etc., is available for all countries that are surveyed.

Table $1^{4}$ : Extortion in Europe (Enterprise Survey 2005, World Bank)

\begin{tabular}{ccccc}
\hline \hline & $\begin{array}{c}\text { Faced Extortion } \\
\text { (\%of firms) }\end{array}$ & $\begin{array}{c}\text { Obs.to Operate } \\
\text { (\%of firms) }\end{array}$ & $\begin{array}{c}\text { Avg. Extortion Payment } \\
(\text { if }>0)\end{array}$ & $\begin{array}{c}10-90 \% \text { Percentile } \\
\text { (if }>0)\end{array}$ \\
\hline Hungary & $5 \%$ & $7 \%$ & 33.6 & {$[.51,104]$} \\
Macedonia & $24 \%$ & $33 \%$ & 23 & {$[2.2,76.8]$} \\
Poland & $13 \%$ & $24 \%$ & 26.4 & {$[.48,133.3]$} \\
Russia & $13 \%$ & $19 \%$ & 49.8 & {$[.42,90]$} \\
Turkey & $23 \%$ & $32 \%$ & 102.9 & {$[1.2,420]$} \\
Ukraine & $7 \%$ & $18 \%$ & 13 & {$[.24,28.7]$} \\
\hline \hline
\end{tabular}

${ }^{4}$ The data in Table 1 is from the Enterprise Survey by the World Bank which provides establishment level data on payments to crime/mafia, which I treat as extortion payments, for a select group of countries (the Appendix contains the full list). The second column documents the fraction of establishments that said other establishments made extortion payments (see Johnson et al (2002) for why this may reflect the establishment's actual experience with extortion). The third column reports the fraction of establishments that stated organized crime/mafia is a major or moderate obstacle to doing business. The last column shows the dispersion in these payments, showing the 10th through 90th percentile of the distribution. 
First, forward looking agents select an occupation based on their expected, post-extortion profit - instead of the first best profit - and the outside wage. TFP and output losses from the selection channel are operative when an agent's occupational choice is altered as a result of extortion. The second source of TFP/output losses can arise through misallocation. Consider an entrepreneur who anticipates that high levels of production can make her more susceptible to extortion. One possibility is that the entrepreneur may reduce production so that she is less of a target for extortion. Alternatively, the entrepreneur may increase production in order to recoup her losses from being extorted. In either situation, when the marginal product of inputs used in production is not set equal to the marginal cost of those inputs, TFP and output losses due to misallocation will arise. In economies where extortion is more prevalent, due to weak property rights, the occupational choice and production decisions can be more severely affected exacerbating TFP and output losses.

To examine how extortion can affect TFP and output, I first build a model to capture the variation in extortion rates that is empirically observed and then calibrate the model to match key moments related to extortion in Poland. The model is a variant of Lucas (1978) where agents are heterogeneous in their ability and choose between starting their own establishment (entrepreneurship) or supplying their labour to existing establishments. There is a criminal group ( $\mathrm{CG}$ ) with monopoly power that is able to extort a share of capital that entrepreneurs use in production, the success of which depends on the strength of property rights in the economy. Entrepreneurs, however, can buy protection to reduce the likelihood of being extorted. The CG, with information on the entrepreneur's choice of capital and protection, chooses the optimal fraction of capital to extort. A central prediction of the model is that while property rights are common across agents the extortion rates they face are heterogeneous and of an inverted ' $u$ ' shape in ability. High ability agents are a prime target for being extorted but they buy sufficient levels of protection which reduce the likelihood of being extorted. Low ability agents buy minimal protection but also use minimal capital in production. Since extortion is costly, it is profitable for the CG to extort little from these agents. Agents of moderate ability face the highest extortion rates because they use sufficient capital to warrant extortion by the CG but are not overly profitable to afford high levels of protection. The variation in extortion rates imply there are heterogeneous responses in entrepreneur production since inputs used in production are chosen to maximize post-extortion profit. Entrepreneurs that face little extortion produce at or close to their optimal capacity but entrepreneurs that face high rates of extortion produce below their optimal capacity. As property rights decrease, a prediction of the model is that extortion rates are higher which induces entrepreneurs produce further below their optimal capacity.

To examine the quantitative effects extortion can have on output and TFP, I calibrate 
the model to match key features in the U.S. economy. The level of property rights for the US is taken from the International Property Rights Index (IPRI) 2009. Since the Enterprise Survey does not contain data for the US or OECD countries, parameters related to the cost of extortion and protection are chosen to target establishment level moments related to extortion and security spending in Poland. The level of property rights are then altered and the resulting equilibrium outcome is compared against an economy that has perfect property rights.

For Poland, I find that the presence of extortion reduces aggregate output and TFP by 8 and 3 percent relative to the first-best economy. Output and TFP changes are due to selection and misallocation. The fraction of entrepreneurs (FOE) falls from 10 to 9.7 percent which increases the average productivity of entrepreneurs in the economy but reduces output because there are fewer operating entrepreneurs. Misallocation occurs as low ability entrepreneurs use little capital in production, below their optimal capacity, in order to reduce the severity in which they are extorted. TFP and output falls as a result. High ability entrepreneurs in contrast buy sufficient protection, face minimal extortion and therefore, produce close to their optimal scale. As property rights weaken output and TFP losses are magnified - both due to selection and misallocation - as a larger set of entrepreneurs face high rates of extortion.

As property rights begin to fall from the first-best level the FOE in the economy decreases. However, there is a threshold level, where further deterioration in the level of property rights increases the FOE. For example, the FOE is about 10 percent in the US but for a country that has about half the level of property rights as the US the FOE can be over 20 percent. When property rights are extremely weak, extortion is ubiquitous and all entrepreneurs reduce capital demand and produce considerably below their optimal scale. Since labour is complimentary in production, the demand for labour falls and so in turn the equilibrium wage. The outside option (the wage) falls by so much that agents enter into entrepreneurship. In this regard, the role that extortion plays is complimentary to the 'entrepreneur out of necessity' theory. ${ }^{5}$

This paper is related to the literature that examines measured TFP and output losses that arise from resource misallocation. Previous work has focused on the role that policy distortions can have in creating resource misallocation. ${ }^{6}$ A common feature of the policy distortions that have been examined are that they are operative only amongst a sub-set of

\footnotetext{
${ }^{5}$ See for example Poschke $(2008 ; 2010)$ who notes that low ability agents pursue entrepreneurship, not due to a great business idea but rather due to a lack of suitable employment opportunities.

${ }^{6}$ For policy distortions related to entry costs see Barseghyan and DiCecio (2011), Moscoso Boedo and Mukoyama (2011), related to firing costs see Poschke (2009) and Hopenhayn and Rogerson (1993), and related to establishment size see Guner, Ventura and $\mathrm{Xu}$ (2008).
} 
establishments in the economy. Extortion is distinct from policy distortions because all establishments can be extorted and to varying degrees. Therefore, extortion affects all establishments either through altering their production or decision to operate. There is also a growing literature that studies how financial frictions, channeled through weak property rights, can generate resource misallocation. ${ }^{7}$ This paper is complimentary to this literature by focusing on the inherent role property rights can have in perpetuating resource misallocation but differs by highlighting how important extortion can be for understanding resource misallocation. In fact, as Johnson et al (2002) find, if property rights are weak (and extortion high), then it is inconsequential whether finance is available.

The results in this paper are also related to the work by Hsieh and Klenow (2009) who find there are large gaps in the marginal product of capital and labour across establishments in China and India. Extortion is one potential explanation for this. Entrepreneurs choose capital and labour to maximize post-extortion profit, and since extortion rates are idiosyncratic the marginal product of capital and labour differ across entrepreneurs. The capital to labour ratio also varies by agent ability and is always lower than the first-best ratio. As such, economies with weak property rights can have aggregate capital to output ratios that are 40 percent lower than in the US. Extortion also offers an alternate explanation for the 'missing-middle' that is documented by Tybout (2000). Since low (high) ability entrepreneurs operate well below (at or close to) their optimal scale, there is a missing middle in the distribution over establishment size. Through the lens of the model, a missing middle exists because extortion induces moderate ability entrepreneurs to operate at an exceptionally small scale. As property rights increase, however, the missing-middle in establishment size gradually disappears. The reason for this is that extortion rates fall as property rights improve which enables entrepreneurs to produce closer to their optimal capacity.

This paper is also related to an earlier literature on extortion/predation. ${ }^{8}$ A distinction is that I examine the macroeconomic implications of extortion in an environment with heterogeneous agents where occupation choice and production decisions are endogenous. The model is tractable and highlights the discriminate impact extortion can have across agents. Also related is Olivella (2010) who examines government expropriation of firm capital via a contracting problem. She finds that firms who receive high productivity shocks reduce investment in order to avoid expropriation while those who receive low shocks invest at the

\footnotetext{
${ }^{7}$ See for example Amaral and Quintin (2010), Buera, Kaboski and Shin (2011), Moll (2010) and Greenwood, Sanchez and Wang (2010) who argue that financial frictions can generate TFP losses. Midrigan and $\mathrm{Xu}(2010)$ is an exception who argue that when a model is fitted to the data TFP losses from financial frictions can be small. Also related is D'Erasmo and Moscoso-Boedo (2011) who examine how an informal sector might arise when property rights are weak.

${ }^{8}$ A few of such papers include Dal Bo and Dal Bo (2006), Choi and Thum (2004), Konrad and Skaperdas (1998), Bliss and Ditella (1997), Grossman and Kim (1995, 1997) and Murphy et al (1993).
} 
optimal level. Our results differ because I consider an environment where entrepreneurs can buy protection, and as such, the highest ability agents face the least amount of extortion.

The remainder of the paper is organized as follows. Section 2 details the model while in Section 3 the model is calibrated. Section 4 presents the results and Section 5 concludes.

\section{Model}

\subsection{Environment}

Agents are heterogeneous with respect to their ability, $s \in S$, and choose between two occupations: being an entrepreneur or earning a wage as a worker. There exists a criminal group (CG) with monopoly power that is able to extort capital from entrepreneurs. ${ }^{9}$ Entrepreneurs use capital and labour to produce and production is given by $y(s)=s k^{\alpha} n^{\gamma}$, with $0<\alpha+\gamma<1$ and $\alpha, \gamma \in(0,1)$. Entrepreneurs can also purchase protection to lower the likelihood of being extorted (discussed in the following sub-section).

If an agent with ability $s$ becomes an entrepreneur and is not extorted by the CG, her profit is given by

$$
\begin{aligned}
\pi(s, k, n) & =s k^{\alpha} n^{\gamma}-w n-(1+r) k+k \\
& =s k^{\alpha} n^{\gamma}-w n-r k .
\end{aligned}
$$

However, if she is extorted by the CG, her profit is

$$
\begin{aligned}
\pi_{e}(s, k, n) & =s k^{\alpha} n^{\gamma}-w n-(1+r) k+(1-e) k \\
& =s k^{\alpha} n^{\gamma}-w n-r k-e k
\end{aligned}
$$

where $e \in(0,1)$ is the fraction of capital that is extorted by the CG. ${ }^{10} e$ is essentially the premium entrepreneurs pay for borrowing capital when there is extortion; if $e$ varies by ability then the effective interest rate entrepreneurs pay for borrowing capital will also vary.

\footnotetext{
${ }^{9} \mathrm{I}$ assume extortion is on capital instead of output because capital is more easily observed by the CG. However, whether extortion is on output or capital is irrelevant to the predictions of the model because there is a direct mapping between capital to output.

${ }^{10}$ It is assumed that the CG's threat of extortion is credible; in that it is always optimal for the entrepreneur to surrender the capital that is demanded by the CG. Dal Bo and Dal Bo (2005) and Konrad and Skaperdas (1997) consider environments where the illegal organizations extort when their threats are not credible.
} 


\subsection{Property Rights}

The economy is characterized by an exogenous level of property rights, $\lambda \in[0,1]$, that is provided by the state and is common across agents. Higher values of $\lambda$ imply better legal protection. The CG is successful in extorting capital with a probability $1-\lambda$; that is, when property rights are higher it is more difficult for the CG to extort entrepreneur capital. Agents can supplement the existing level of property rights through purchasing protection, which reduces the likelihood of being extorted. ${ }^{11}$ An agent's effective rate of protection (ERP), after buying protection, is given by $F(\lambda, z)=\lambda+\lambda z(s)^{\theta} \in[0,1]$ with $\theta>0$ and $z(s) \in[0, \bar{z}]$ is the amount of protection bought. While $\lambda$ is common across agents the ERP can vary across agents based on the amount of protection that is purchased. The CG extorts capital successfully, from an entrepreneur of type $s$, at a rate of $1-F(\lambda, z)$. The success rate is decreasing in both the level of property rights and protection bought. Since the ERP cannot be greater than one, the maximum amount of protection an agent can buy is $\bar{z}=\left(\frac{1-\lambda}{\lambda}\right)^{\frac{1}{\theta}}$, which is non-binding in equilibrium.

\subsection{Agent and CG Decisions}

\subsubsection{Agent Decisions}

The decision facing all agents (or potential entrepreneurs) is to determine how much capital and labour inputs to use in production and how much protection to purchase in order to limit the likelihood of being extorted. Since agents anticipate that the CG will extort a fraction $e \in[0,1]$ of capital, successfully at a rate of $1-F(\lambda, z)$, agents choose capital and labour to maximize post-extortion profit. The problem of the potential entrepreneur is given by

$$
\widetilde{\pi}(s)=\max _{k, n \geq 0} \widehat{\pi}(s, k, n)
$$

where

$$
\begin{aligned}
\widehat{\pi}(s, k, n) & =\max _{z \in[0, \bar{z}]} F(\lambda, z) \pi(s, k, n)+(1-F(\lambda, z)) \pi_{e}(s, k, n)-\frac{b z^{\psi}}{\psi} \\
& =\max _{z \in[0, \bar{z}]} \pi(s, k, n)-(1-F(\lambda, z)) e k-\frac{b z^{\psi}}{\psi} .
\end{aligned}
$$

\footnotetext{
${ }^{11}$ Protection that is purchased by the entrepreneur is of the legitimate type - legal, private security -and not extortion in disguise. That is, when entrepreneurs buy protection it is not to 'buy-off' the threat of extortion where the payment ultimately arrives in the hands of the would be extorter.
} 
Equation 4 states that with a probability $F(\cdot)$ an entrepreneur of ability level $s$ is not extorted, earning profit $\pi(s, k, n)$ and with probability $1-F(\cdot)$ the entrepreneur is extorted and earns profit $\pi_{e}(s, k, n)$. This expression can be further simplified to imply the entrepreneur earns her full profit from production less the fraction of capital that is extorted, $e(s) \in(0,1)$, which occurs with a probability $1-F(\cdot)$. The entrepreneur then chooses the amount of protection to buy to minimize the likelihood of being extorted subject to the marginal cost of buying protection $\left(\frac{b z^{\psi}}{\psi}\right)$. Finally, capital and labour are chosen to maximize $\widehat{\pi}(s, k, n){ }^{12}$ An entrepreneur of type $s^{\prime}$ post-extortion profit is given by $\tilde{\pi}(s)$. When $\lambda=1$, choosing capital and labour to maximize post-extortion profit $(\widehat{\pi})$ reduces to maximizing $\pi$ as in the first-best case. ${ }^{13}$ However, when $\lambda<1$ there can be misallocation of capital and labour as entrepreneurs choose inputs to maximize over post-extortion profit. The first best outcome may be infeasible.

The second channel which generates inefficiency arises through selection - entry into entrepreneurship. The occupational choice decision for an agent of type $s$ is given by $V(s)=$ $\max \{\tilde{\pi}(s), w\}$. Agent entry into entrepreneurship is based on post-extortion profit instead of first-best profit. Therefore, inefficiency through the selection channel occurs whenever $\tilde{\pi}(s ; w)<w \leq \pi(s ; w)$; that is, when an agent forgoes entry into entrepreneurship due to the presence of extortion.

\subsubsection{CG Decisions}

The Criminal Group has monopoly power and complete information on entrepreneur capital and protection decisions. ${ }^{14}$ Extortion is costly since the CG has to spend time initiating contact, monitoring and collecting extortion rents. The fraction of capital that is extorted from an entrepreneur with ability level $s$ is chosen to maximize

$$
\Pi_{C G}(s)=\max _{e \in[0,1]}(1-F(\lambda, z)) k(s) e(s)-\frac{a e^{\rho}}{\rho} .
$$

The CG successfully extorts a fraction $e(s)$ of entrepreneur capital with a probability $1-F(\cdot)$. Variation in capital and protection choices by the entrepreneur imply that extortion rates will differ across entrepreneurs. The marginal cost of extortion is assumed to be convex $(\rho>1) \cdot{ }^{15}$

\footnotetext{
${ }^{12}$ It is equivalent to think of the problem as the entrepreneur choosing capital, labour and protection simultaneously.

${ }^{13} \lambda=1 \Longrightarrow \bar{z}=0$ and therefore $1-F(\lambda, z)=0$.

${ }^{14}$ The monopoly power assumption is a modeling convenience. Agents care about the amount that is being extorted and not which group(s) is doing the extorting.

${ }^{15}$ Extorting a larger fraction of the entrepreneur's capital requires more resources on the part of the CG. For example, Gambetta (2000) notes that when large values of profit is extorted by the mafia, multiple visits
} 


\subsection{Timing and Solution Concept}

The timing of agent and CG decisions are as follows. Agents choose one of two occupations: entrepreneur or worker. ${ }^{16}$ Workers supply their labour to hiring entrepreneurs while entrepreneurs decide how much to produce (using capital and labour) and how much protection to purchase. The CG has full information on the decisions made by the entrepreneur and chooses the optimal fraction of capital to extort.

Given the timing sequence, the optimal protection, production and extortion choices can be solved via a two-stage game where the entrepreneur moves first and the CG moves second. All entrepreneurs therefore choose capital, labour and protection in anticipation of the CG's best response for extortion. The CG's best response function is

$$
e^{b r}(s)=\left(\frac{(1-F(\lambda, z(s)) k(s)}{a}\right)^{\frac{1}{\rho-1}}
$$

and can be obtained by solving (5). Given the CG's best response each entrepreneur chooses an optimal level of protection.

Proposition 1 If $\theta=\frac{\psi(\rho-1)}{\rho}$, a closed form solution for the optimal level of protection exists. This level is dependent on capital and is given by

$$
z^{*}(s)=\left(\frac{\Omega^{\rho-1} \lambda^{\rho-1}(1-\lambda) k(s)^{\rho}}{a+\Omega^{\rho-1} \lambda^{\rho} k(s)^{\rho}}\right)^{\frac{1}{\theta}},
$$

where $\Omega=\frac{\theta}{b} \frac{\rho}{\rho-1}=\frac{\psi}{b}$. It follows that $z^{*}(s)<\bar{z} \forall s$. All proofs are in the Appendix. Given $z^{*}(s)$, the optimal fraction of capital that is extorted by the CG, for any choice of capital chosen by the entrepreneur, is given by

$$
e^{*}(s)=\left(\frac{(1-\lambda) k(s)}{a+\Omega^{\rho-1} \lambda^{\rho} k(s)^{\rho}}\right)^{\frac{1}{\rho-1}} .
$$

Extortion by the CG is decreasing in property rights; as property rights increase the probability of successfully extorting decreases. Given (6) and (7) the optimal choice of labour and (monitoring) to the entrepreneur are required.

${ }^{16}$ I abstract from an agent's decision to become an extorter or a protection provider. As long as the income from being an extorter or protection provider is independent of ability, then in equilibrium those earnings will equal the wage of a worker; or else all agents who are not entrepreneurs will choose the occupation that provides them with the highest income. As such, I abstract from these additional occupation choices. For papers that do examine the decision to become an extorter see Acemoglu (1995), Grossman and Kim (1995, 1997). 
capital is determined by solving (3). ${ }^{17}$ When $\lambda<1$, extortion and protection are always greater than zero and varies by agent ability.

\subsection{Comparative Statics}

I now examine how extortion and protection decisions vary by agent ability and the level of property rights in the economy.

Proposition 2 Post-extortion profit, $\tilde{\pi}(s)$, is non-decreasing in agent ability.

Assumption 1: capital is non-decreasing and continuous in agent ability $\left(\frac{\partial k}{\partial s} \geq 0\right)$ and $\rho>1$ and $\theta>0$.

Proposition 3 Using Assumption 1, then protection is increasing in agent ability. Moreover, there is an ability threshold $\widehat{s}$, such that agents with ability $s \leq \widehat{s}$ buy protection at an increasing rate while agents with ability $s>\widehat{s}$ buy protection at a decreasing rate.

Proposition 4 Given Assumption 1, there is a critical level of property rights - $\lambda^{c}=\frac{\rho-1}{\rho}$ such that when $\lambda \geq \lambda^{c}$, protection and property rights are substitutes. When property rights are below this critical level, protection and property rights are complimentary for low ability agents and substitutes for all others.

Proposition 5 The effective rate of protection, $F(\lambda, z)$, is increasing in agent ability and the level of property rights.

Proposition 2 states that high ability agents earn more from entrepreneurship than low ability agents. A high ability agent can always choose the same level of capital and protection that a low ability agent chooses and earn higher post-extortion profit. Proposition 3 and 4 detail agent protection decisions by ability. Protection purchases are increasing in ability and of a ' $\mathrm{S}$ ' shape. Property rights have heterogeneous effects with respect to agent protection decisions. When property rights are above a critical threshold $\left(\lambda^{c}\right)$, protection and property rights are substitutes; that is, further increases in property rights induce agents to buy less protection. The state provides a sufficient level of protection and since protection is costly buying additional protection is not optimal. However, when property rights are weak, or below $\lambda^{c}$, protection and property rights are complimentary for low ability agents - those

\footnotetext{
${ }^{17}$ There is no closed form solution for the optimal choice of capital or labour and must be solved numerically. In Section 2.7, I consider a special case and show how capital can deviate from the first-best level and vary by entrepreneurial ability.
} 

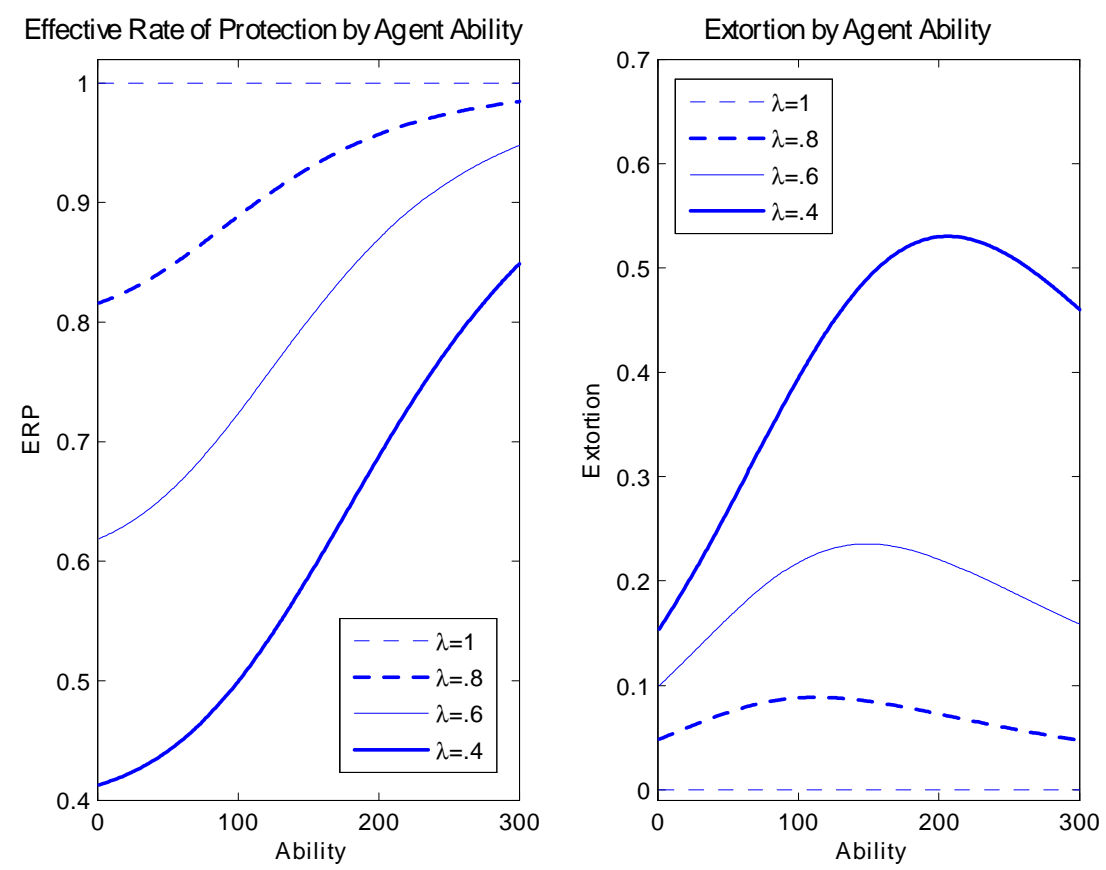

Figure 2: Property rights and the variation in protection and extortion across agents when $\rho=$ $\psi=2$.

below some ability threshold. Since property rights are weak, a large amount of protection is required to offset the threat of extortion. However, low ability agents are not sufficiently profitable to warrant such expenditure on protection. When property rights begin to improve, low ability agents increase protection purchases since protection and property rights are complimentary to an agent's effective rate of protection (ERP). ${ }^{18}$ Finally, Proposition 5 states that the ERP is increasing in agent ability and, holding agent ability fixed, agents in economies with higher property rights have a higher ERP.

Proposition 6 Using Assumption 1, there is an ability threshold $s_{x}(\lambda)$ such that extortion is increasing in agent ability for all $s \leq s_{x}(\lambda)$ and decreasing otherwise. Moreover, the ability threshold is decreasing in property rights, that is $\frac{\partial s_{x}(\lambda)}{\partial \lambda} \leq 0$.

Proposition 6 states that extortion is an inverted ' $u$ ' in agent ability. This result comes directly from agents being able to mitigate extortion through purchasing protection. ${ }^{19}$ High ability agents, who use the most capital, do not face the highest levels of extortion because they buy a large amount of protection. Low ability agents face little extortion because

\footnotetext{
${ }^{18}$ This result holds whenever the functional form for the ERP exhibits $F_{z}, F_{\lambda}>0$ and $F_{z \lambda}>0$.

${ }^{19}$ Extortion would be strictly increasing in agent ability if protection is not available, similar to previous work that have examined extortion without protection.
} 
it is not worthwhile for the CG to incur costs in order to extort the little capital that is used in production. Agents of moderate ability face the most extortion because they are neither sufficiently profitable to warrant large expenditures on protection, nor extremely unproductive to use little capital in production. Moreover, the ability level of the agent that faces the most extortion is decreasing in the level of property rights. That is, in economies with lower property rights it is always a higher ability agent that faces the most extortion.

Figure 2 depict Proposition 5 and 6 graphically.

\subsection{Equilibrium}

I focus on a sequential game equilibrium where agent decisions precede extortion decisions by the CG. An equilibrium consists of a series of decision rules for agents given by $k(s)$, $n(s), z(s)$ and $V(s)$, and extortion decisions by the CG, $e(s)$, such that given prices $(w, r)$ and a distribution over ability, $\mu(s)$,

1. Agents choose occupations based on $V(s)=\max \{\tilde{\pi}(s), w\}$.

2. Entrepreneurs choose protection to solve (4) and capital and labour to solve (3).

3. The CG chooses the fraction of capital to extort, for each entrepreneur of type $s$, to solve (5).

4. Markets clear,

$$
\begin{gathered}
\int_{S_{E} \in S} n^{*}(s) d \mu(s)=\int_{S \backslash S_{E}} d \mu(s), \\
\int_{S_{E} \in S} k^{*}(s) d \mu(s)=K \\
\int_{S_{E} \in S} y^{*}(s) d \mu(s)=Y, \\
\int_{S_{E} \in S} z^{*}(s) d \mu(s)=Z \\
\int_{S_{E} \in S}\left(1-F(\lambda, z(s)) e^{*}(s) k^{*}(s) d \mu(s)=E\right.
\end{gathered}
$$

where $S_{E}$ denotes the set of entrepreneurs in the economy. Equation 8 is the labour market clearing condition which states that the demand for labour by all entrepreneurs must be equal to the supply of labour by all workers. The equilibrium wage is the one that clears the labour market. Equations 9-11 are for aggregate capital, output and protection. Finally, equation 
12 is the aggregate extortion of capital which takes into consideration the probability of successfully extorting across entrepreneur ability.

\subsection{Special Case}

To explicitly examine how misallocation can arise in the model, I consider a special case where $\rho=\psi=b=2$ (which simplifies the algebra that follows). When property rights are less than one, extortion will induce agents to select capital where the marginal product of capital (MPK) is greater than the cost of capital. Substituting the values for $\rho, \psi$ and $b$ into equation (7) and (8) yield

$$
z^{*}(s)=\frac{\lambda(1-\lambda) k(s)^{2}}{a+\lambda^{2} k(s)^{2}} \text { and } e^{*}(s)=\frac{(1-\lambda) k(s)}{a+\lambda^{2} k(s)^{2}}
$$

By further substituting the optimal values for protection and extortion into equation (4), we can examine how entrepreneurs choose capital and labour inputs in production. Doing so implies

$$
\widetilde{\pi}(s)=\max _{k, n \geq 0} \pi(s, k, n)-\frac{(1-\lambda)^{2} k(s)^{2}}{a+\lambda^{2} k(s)^{2}} .
$$

Implicitly differentiating equation (13) implies that capital is increasing in entrepreneur ability, $\frac{\partial k(s)}{\partial s} \geq 0$.

Proposition 7 When $\lambda<1$ but not too close to zero, all entrepreneurs, except for the highest ability ones, choose capital below the optimal level which generates a misallocation in capital. Furthermore, the deviation from the optimal level is an inverted ' $u$ ' shape in agent's ability.

To see this, differentiating equation (13) with respect to capital yields,

$$
\begin{aligned}
\frac{\partial \pi(s)}{\partial k(s)}-\xi(\lambda, k) & =0, \\
M P K & =r+\xi(\lambda, k) .
\end{aligned}
$$

where $\xi(\lambda, k)=\frac{2 a(1-\lambda)^{2} k(s)}{\left(a+\lambda^{2} k(s)^{2}\right)^{2}} \geq 0$. Misallocation will arise whenever agents do not set the marginal product of capital equal to the rental rate of capital. From equation (14), when $\lambda=1, \xi=0$; all agents choose capital where the $M P K=r$. When $\lambda<1$, the $M P K>r$ for everyone except the highest ability agents. ${ }^{20}$ As $k \rightarrow \infty$ the $M P K \rightarrow r,(\xi \rightarrow 0)$. An

\footnotetext{
${ }^{20}$ Despite entrepreneurs choosing labour where the $M P L=w$ (see equation 13, labour enters only through $\pi(s)$ ), when the $M P K>r$, labour demand is also misallocated because labour is a function of capital.
} 
implication is, in economies where property rights are not too low, high ability entrepreneurs operate close to the optimal scale ( below the optimal scale. For the final part of the proposition, differentiating $\xi$ with respect to capital yields an inverted ' $u$ ' shape in agent's ability. $\xi$ is the premium for borrowing capital as a result of extortion, which is heterogeneous across agents.

\section{Calibration}

The model is calibrated to match key features in the US taking as given the level of property rights, $\lambda_{U S}$. I use the International Property Rights Index (IPRI) score, as detailed in the IPRI 2009 report, as my measure of property rights. ${ }^{21}$ Parameters that require calibration are the elasticities on the production function $(\alpha, \gamma)$, parameters related to the cost function of extortion $(a, \rho)$, parameters related to the cost of protection $(b, \psi)$, the complementarity between protection and property rights $(\theta)$, the interest rate $(r)$ and the distribution over agent ability $(\mu(s))$. Once these parameters are determined, I alter $\lambda$ and examine the equilibrium outcome.

For the decreasing returns to scale production function, I set $\alpha$ and $\gamma$ to 0.283 and 0.567 , respectively, so that they sum to 0.85 as is standard in the literature. Following Buera and Shin (2010), I assume that agent ability is Pareto distributed with a smoothing parameter, $\eta=4.95$, in order to target that the fraction of entrepreneurs (FOE) in the U.S. economy is 10 percent. $^{22}$ The interest rate together with the end points in the ability distribution are chosen to target a capital to output ratio of 2.65 (see Quadrini, 2000).

Parameters that remain to be determined are $\rho, \psi, a$ and $b$. I use Polish data as provided in the World Bank Enterprise Survey, that has over 600 cross section observations at the firm level, to pin down these parameters. Since the IPRI score for Poland is $\lambda_{P o l}=0.53$, I choose $\rho, \psi, a$ and $b$ to minimize the sum of squares distance between the predictions of the model when $\lambda=0.53$ against the following four targets: the average extortion to capital ratio, the average protection to capital ratio, the average extortion to capital ratio in the fifth decile of the sample relative to the first decile in the sample, and likewise the average

\footnotetext{
${ }^{21}$ The IPRI is a composite score of three variables: legal/political environment, physical property rights and intellectual property rights. The score is a cardinal ranking that takes values between 0 and 10 with most countries falling in the range of 2 to 9 . I divide these values by 10 so that they are between 0 and 1 to be comparable with $\lambda$. The score maps well to the interpretation of $\lambda$ in the model if countries that have higher IPRI scores are better at preventing extortion/theft. Alternate mappings between the IPRI score to $\lambda$ (i.e. $g($ score $) \rightarrow(0,1)$ where $g(\cdot)$ is an increasing function) can be considered without significant alterations to the results in Section 4.

${ }^{22}$ The FOE in the U.S. can range between 7-16 percent depending on the exact definition one uses to describe an entrepreneur (see Cagetti and DeNardi 2006). I target a lower bound of this range so that my results are a conservative gauge of output and TFP losses.
} 
protection to capital ratio in the fifth decile of the sample relative to the first decile in the sample. I focus on the case where a closed form solution for protection exists which implies that $\theta=\frac{\psi(\rho-1)}{\rho}$. Table 2 summarizes these parameter values and targets.

Table 2: Parameter Values and Targets

\begin{tabular}{cccc}
\hline \hline Parameter & Value & Target & Model \\
\hline$s \in S$ & {$[1.5,4]$} & Pareto Dist. & \\
$\eta$ & 4.95 & FOE, $10 \%$ & $10 \%$ \\
$\alpha, \gamma$ & $0.283,0.567$ & Prod. fcn & \\
$r$ & 0.24 & $\frac{K}{Y}=2.65$ & 2.65 \\
$a$ & 2.28 & $\left(\frac{E}{K}\right)_{a v g .}=0.015$ & 0.015 \\
$b$ & 9.08 & $\left(\frac{Z}{K}\right)_{a v g .}=0.014$ & 0.0134 \\
$\rho$ & 1.26 & $\frac{\left(\frac{E}{K}\right)_{d 5, \text { avg. }}}{\left(\frac{E}{K}\right)_{d 1, \text { avg. }}}=0.9$ & 0.95 \\
$\psi$ & 1.42 & $\frac{\left(\frac{Z}{K}\right)_{d 5, a v g .}}{\left(\frac{Z}{K}\right)_{d 1, a v g .}}=1.83$ & 1.57 \\
\hline \hline
\end{tabular}

Table 3 presents results for how well the model fits the extortion and protection data in Poland, broken down by quartiles in firm level capital. The model does quite well in fitting the data despite not being targeted to fit such moments.

Table 3: Model Fit by Capital Distribution

\begin{tabular}{ccc|cc}
\hline \hline & \multicolumn{2}{c}{$\left(\frac{E}{K}\right)_{\text {avg. }}$} & \multicolumn{2}{c}{$\left(\frac{Z}{K}\right)_{\text {avg. }}$} \\
\cline { 2 - 5 } & Data & \multicolumn{1}{c}{ Model } & Data & Model \\
\hline 1st Quartile & 0.025 & 0.026 & 0.011 & 0.014 \\
2nd Quartile & 0.018 & 0.025 & 0.014 & 0.018 \\
3rd Quartile & 0.008 & 0.007 & 0.018 & 0.014 \\
4th Quartile & 0.009 & 0.002 & 0.012 & 0.008 \\
\hline \hline
\end{tabular}

For the property rights in a given country I have used the IPRI 2009 Report as a measure for $\lambda$. Because the IPRI score is a cardinal ranking it maps reasonably well to the interpretation of $\lambda$ in the model. For example, if country A and country B have a score of 4 and 8 , then country $\mathrm{B}$ has twice the level of property rights. In the context of the model, country $\mathrm{B}$ is twice as likely to prevent the $\mathrm{CG}$ from extorting entrepreneur capital. While the IPRI score may not be the ideal counterpart to $\lambda$ in the model, finding an exact mapping from the data to $\lambda$ is problematic. Nonetheless, as a robustness check I re-run the calibration exercise described above for Poland but include $\lambda$ in the sum of squares minimization. I find that the parameters that minimize the distance between the model and data are similar to 
those listed in Table 2 and the implied $\lambda$ is about 0.56 . This is very close to $\lambda_{P o l}=0.53$ found in the IPRI Report, which suggests that, at least for Poland, the IPRI score may be an adequate mapping to $\lambda$ in the model.

\subsection{Aggregation and TFP}

Given the closed form solution for $z^{*}(s)$ and $e^{*}(s)$ from (6) and (7) then the optimal choice for capital and labour is determined from equation (3). Since there is no closed form solution for capital or labour, the optimal choices must be determined through a grid search. However, since the grid search is over all combinations of capital and labour, solving for optimal capital and labour is computationally tedious. A more convenient approach is to substitute the optimal choice of labour into the production function so that the production function is only in terms of capital. ${ }^{23}$ Doing so implies

$$
\pi(s)=A s^{\frac{1}{1-\gamma}} k^{\frac{\alpha}{1-\gamma}}-r k
$$

where $A=(1-\gamma)\left(\frac{\gamma}{w}\right)^{\frac{\gamma}{1-\gamma}}$. The grid search is only over capital and the optimal labour input can be backed-out from the first order condition for labour. None of the results in Section 2 are affected by rewriting the production function in the above manner.

Aggregating up the output of every operating entrepreneur when $\lambda=1$ generates the following aggregate production function

$$
Y=\Phi_{\lambda=1} \zeta K^{\frac{\alpha}{1-\gamma}}
$$

where $\zeta=A N^{\frac{1-\alpha-\gamma}{1-\gamma}}, N=\int_{s \in S_{E}} d \mu(s)$, and $\Phi_{\lambda=1} \equiv\left(\frac{1}{N} \int_{s \in S_{E}} s^{\frac{1}{1-\alpha-\gamma}} d \mu(s)\right)^{\frac{1-\alpha-\gamma}{1-\gamma}}$ is measured TFP or the average productivity of entrepreneurs in the first-best economy. When $\lambda<1$, there is no closed form solution for capital and therefore, defining the aggregate production function and TFP is not possible. However, given the structure in equation (15), TFP for an economy is given by $T F P=Y\left(\zeta K^{\frac{\alpha}{1-\gamma}}\right)^{-1}$. Furthermore, I attempt to back out TFP losses due to selection $\left(\triangle T F P_{\text {sel }}\right)$ and misallocation $\left(\triangle T F P_{\text {mis }}\right)$ in the following way. By holding production at the optimal level for a given equilibrium wage in the economy, I can measure TFP changes that arise from selection directly from $\Phi_{\lambda} \equiv T F P_{\text {sel }}$. These are changes in TFP that arise due to changes in the composition of entrepreneurs in the economy but not due to distortions in production. The change in TFP that cannot be accounted for by

\footnotetext{
${ }^{23}$ Because $e^{*}(s)$ and $z^{*}(s)$ are independent of $n(s)$, then optimal labour is dependent only on capital solving equation 4 implies $n^{*}(s)=\left(\frac{\gamma s k^{\alpha}}{w}\right)^{\frac{1}{1-\gamma}}$. Therefore, writing the production function only in terms of capital does not alter the entrepreneur or CG's problem.
} 
selection must then be due to misallocation. It follows that $\triangle T F P_{m i s}=\frac{T F P_{s e l}-T F P_{\lambda}}{T F P_{f b}-T F P_{\lambda}}$ and $\Delta T F P_{\text {sel }}=\frac{T F P_{f b}-T F P_{s e l}}{T F P_{f b}-T F P_{\lambda}}$ (see Appendix).

\section{Results}

In this Section the level of property rights, $\lambda$, is varied to study the effect extortion can have on equilibrium outcomes of interest. I first present the effect extortion has on aggregate variables and then proceed to discuss the micro effects across agents.

\subsection{Aggregate and TFP Effects}

Table 4 presents the aggregate results for economies with varying levels of property rights. I consider values of $\lambda$ between 0.3 to 0.8 , as most countries' property rights lie within this range. All variables are relative to the first-best economy $(\lambda=1)$; an economy in which there is no opportunity for extortion. A general theme is that as property rights decrease, extortion increases but TFP, aggregate capital and output, and the equilibrium wage fall. The fraction of entrepreneurs (FOE) initially falls as $\lambda$ decreases but then surpasses the first-best level for further decreases in $\lambda$ (in the following Section I explain why this occurs).

For the economy with property rights closest to the level of the US $\left(\lambda_{U S} \approx 0.7\right)$, TFP and aggregate output losses from extortion are negligible. Since property rights are reasonably high, entrepreneurs need to buy only minimal protection to ensure that they cannot be extorted; the economy operates very close to the first-best level. As property rights decrease, however, the aggregate effect on TFP, output and the capital to output ratio are more noticeable. For example, a prediction of the model for Poland, which the model is calibrated to, is that extortion reduces aggregate output by 8 percent and TFP by 3 percent relative to the first-best economy. The capital to output (CL) ratio is 15 percent lower. Further decreases in property rights produce larger aggregate output and TFP losses. ${ }^{24}$ When property rights are weak, only the highest ability entrepreneurs can afford to purchase sufficient protection to avoid being extorted. All other entrepreneurs, therefore, intentionally choose to operate below their optimal scale which generates TFP and output losses. For example, when $\lambda=0.45$, aggregate output and TFP losses are over 25 and 10 percent, respectively.

\footnotetext{
${ }^{24} \mathrm{TFP}$ is higher in the economy with $\lambda=0.35$ than $\lambda=0.45$. Property rights are extremely weak such that all entrepreneurs demand very little capital. Since the production function is DRS, TFP in the economy is higher than an economy with higher property rights, but still lower than the first-best economy.
} 
Table 4: Impact of $\lambda$ across Economies

\begin{tabular}{cccccc}
\hline \hline & $\lambda_{f b}=1$ & $\lambda=0.7$ & $\lambda_{\text {Pol }}=0.53$ & $\lambda=0.45$ & $\lambda=0.35$ \\
\hline rel $Y$ & 1 & 0.996 & 0.92 & 0.74 & 0.62 \\
rel TFP & 1 & 1 & 0.97 & 0.89 & 0.94 \\
rel $\frac{K}{Y}$ & 1 & 0.995 & 0.85 & 0.57 & 0.36 \\
FOE & $10 \%$ & $9.9 \%$ & $9.7 \%$ & $16.3 \%$ & $21.6 \%$ \\
rel. wage & 1 & 0.995 & 0.92 & 0.79 & 0.73 \\
\hline \hline
\end{tabular}

As this is a model that studies the extensive and intensive margins of entrepreneurship, I decompose changes in TFP and output that arise due to selection (extensive margin) and misallocation (intensive margin). TF $P_{\text {sel }}$ and $Y_{\text {sel }}$ denote the TFP and aggregate output level in the distorted economy if production was at the optimal level $(M P K=r)$ but where the composition of entrepreneurs is at the distorted economy's level; that is, an economy in which there is no misallocation but where the selection channel is operative. As shown in Table 4, $\frac{T F P_{s e l}}{T F P_{f b}} \geq \frac{T F P_{\lambda}}{T F P_{f b}}$ for all values of $\lambda$, suggesting that extortion induces many entrepreneurs to operate below the optimal capacity. $\triangle T F P_{m i s}$ is the change in TFP that is due to misallocation, between the first-best and distorted economy $\left(\triangle T F P_{\text {sel }}=1-\Delta T F P_{\text {mis }}\right)$. When $\lambda=0.5, \Delta T F P_{m i s}=97 \%$ and $\triangle T F P_{\text {sel }}=3 \%$; the fraction of (and the composition of) entrepreneurs in the economy is close to the first-best level and hence there is little effect along the selection channel. When $\lambda=0.3, \Delta T F P_{\text {mis }}=77 \%$ and $\Delta T F P_{\text {sel }}=23 \%$. The selection channel becomes prominent in generating TFP losses because the entry threshold for entrepreneurship is lower (see Section 4.2); the FOE is higher and the average productivity of entrepreneurs in the economy is lower. Turning to output, when $\lambda=0.4, \frac{Y_{\lambda}}{Y_{f b}}=0.65$ but $\frac{Y_{s e l}}{Y_{f b}}=4.16$. If entrepreneurs operated at their optimal scale aggregate output would be 4 times higher than the first-best economy. There is a larger FOE in the distorted economy and the equilibrium wage is lower, hence, output should be significantly higher. The fact that $\frac{Y_{\lambda}}{Y_{f b}}=0.65$ implies that entrepreneurs operate significantly below their optimal scale.

Table 5: Decomposing changes in TFP and Output

\begin{tabular}{ccccc}
\hline \hline & $\lambda=0.6$ & $\lambda=0.5$ & $\lambda=0.4$ & $\lambda=0.3$ \\
\hline$\frac{T F P_{\lambda}}{T F P_{f b}}$ & $\approx 1$ & 0.94 & 0.93 & 0.94 \\
$\frac{T F P_{s e l}}{T F P_{f b}}$ & $\approx 1$ & 0.998 & 0.987 & 0.986 \\
$\Delta T F P_{m i s}$ & - & $97 \%$ & $76 \%$ & $77 \%$ \\
$\frac{Y_{\lambda}}{Y_{f b}}$ & 0.98 & 0.88 & 0.65 & 0.6 \\
$\frac{Y_{s e l}}{Y_{f b}}$ & 1.07 & 1.68 & 4.16 & 5.36 \\
\hline \hline
\end{tabular}




\subsection{Effect Across Agents}

Figures 3,4 and 5 present the results when $\lambda=0.7$ ( $\approx$ US economy), $\lambda=0.53$ (Polish economy) and when $\lambda=0.45$, respectively. In the US economy, misallocation is minimal, capital demand is indistinguishable from the first-best level, and the ability threshold for entry into entrepreneurship is marginally higher (selection effect). The effective rate of extortion $\left(e^{*}(s)(1-F)\right)$ is an inverted ' $\mathrm{u}$ ' in agent ability but strictly decreasing in entrepreneur ability (only the most productive agents enter into entrepreneurship). Because property rights are high in the US, buying minimal protection is sufficient for entrepreneurs to reduce the likelihood of being extorted; they have an effective rate of protection, $F(\lambda, z) \approx 1$. The capital to labour (CL) ratio is below the first best level for low ability agents (though they do not select into entrepreneurship) and marginally below the first-best level for those who are entrepreneurs.

For the economy with $\lambda=0.53$ and 0.45 (see Figure 4 and 5), there is a discontinuity in capital demand across agents, which coincides with the discontinuity in extortion and protection choices agents encounter/make. ${ }^{25}$ There is a critical threshold level of ability, $s_{x}(\lambda)$, where agents with ability $s \leq s_{x}(\lambda)$ choose capital below the first-best level and agents with ability above $s_{x}$ choose capital above the first-best level. The point of discontinuity is decreasing in property rights, $\frac{\partial s_{x}(\lambda)}{\partial \lambda} \leq 0$; that is, as property rights decrease a larger set of entrepreneurs choose capital below the first-best level, similar to Proposition 6 in Section 2. As entrepreneurs choose capital below the first-best level the distribution over establishment size is affected. As shown in Figure 7, extortion results in a disproportionally higher number of small and large establishments while there are fewer mid-size establishments. For the economy with $\lambda=0.45$, the distribution over establishment size exhibits a missing middle. The majority of establishments operate at a very small scale while the few entrepreneurs that can afford to buy sufficient protection face little extortion. Together with the low equilibrium wage they operate as mega-size establishments.

The intuition behind an agent's capital choice is as follows: low ability agents, those with $s \leq s_{x}$, buy minimal protection as they are not sufficiently productive (low ability) to recoup the cost of large protection expenditures. Failure to spend on protection implies that the CG can extort with a high probability of success (since property rights are weak). Foreseeing this, low ability agents operate at a smaller scale. There are TFP losses due to misallocation because capital is below the optimal level (the $M P K>r$ ). Conversely, high ability agents, those with $s>s_{x}(\lambda)$, buy a large amount of protection, have an ERP close to one and therefore face effective extortion rates close to zero. These agents operate close to

\footnotetext{
${ }^{25}$ Protection acts as fixed cost leading to a discontinuity in capital across agents. $e^{*}(s)$ and $z^{*}(s)$ are discontinuous because they are functions of $k^{*}(s)$.
} 
the optimal scale choosing capital where the $M P K \approx r$. High ability agents in the distorted economy are larger - in terms of capital and labour demand - than agents of similar ability in the first-best economy. The equilibrium wage in the distorted economy is lower resulting in higher capital demand by high ability agents (See Figure 6). ${ }^{26}$ Nonetheless, the CL ratio for agents in the distorted economy is below the CL ratio for agents of similar ability in the first-best economy. Moreover, the CL ratio is inversely related to the effective extortion rate: agents that face the highest rates of extortion have the lowest CL ratios in production. This is especially important for understanding TFP losses given that $\frac{\partial s_{x}(\lambda)}{\partial \lambda} \leq 0$; in economies with weak property rights, a larger set of entrepreneurs produce below the optimal scale.

As agent choices of capital are altered as a result of extortion, so in turn are the occupational choice decisions they make. For economies with $\lambda \in[0.6,1)$, extortion increases the ability threshold required for entry into entrepreneurship. For agents near the entry threshold, buying protection in order to reduce the extortion rates they face imply that post-extortion profit is less than the outside option, the equilibrium wage. These are agents that should operate as entrepreneurs in the economy - $\tilde{\pi}(s ; w)<w<\pi(s ; w)$ - however, anticipated losses from extortion induce them to forgo entrepreneurship. Measured TFP, or the average productivity of entrepreneurs, in the economy is higher because there is a higher threshold for entry into entrepreneurship.

As property rights decrease from the first-best level, entry into entrepreneurship falls as extortion becomes more prevalent. However, as property rights decrease further entry into entrepreneurship begins to increase. For example, the FOE is 9.9 percent when $\lambda=0.7$ but over 16 percent when $\lambda=0.45$ (see Table 3 ). When property rights are weak, the effective rate of extortion is so high such that entrepreneurs demand very low levels of capital. Since capital and labour are complimentary in production, the demand for labour falls. As a result, the equilibrium wage is significantly lower. More agents select into entrepreneurship because their outside option is lower. Agents select into entrepreneurship not due to a great business idea (or high ability in this case) but rather due to a weak outside option, similar to the 'entrepreneur out of necessity' theory as noted by Poschke (2010). ${ }^{27}$

\footnotetext{
${ }^{26}$ This implies, because they face lower wages, all entrepreneurs in the distorted economy should be larger than entrepreneurs of similar ability in the first-best economy.

${ }^{27}$ The 'entrepreneur out of necessity' theory is also one in which entry into entrepreneurship is nonmonotonic in ability. My model does not capture this particular feature.
} 

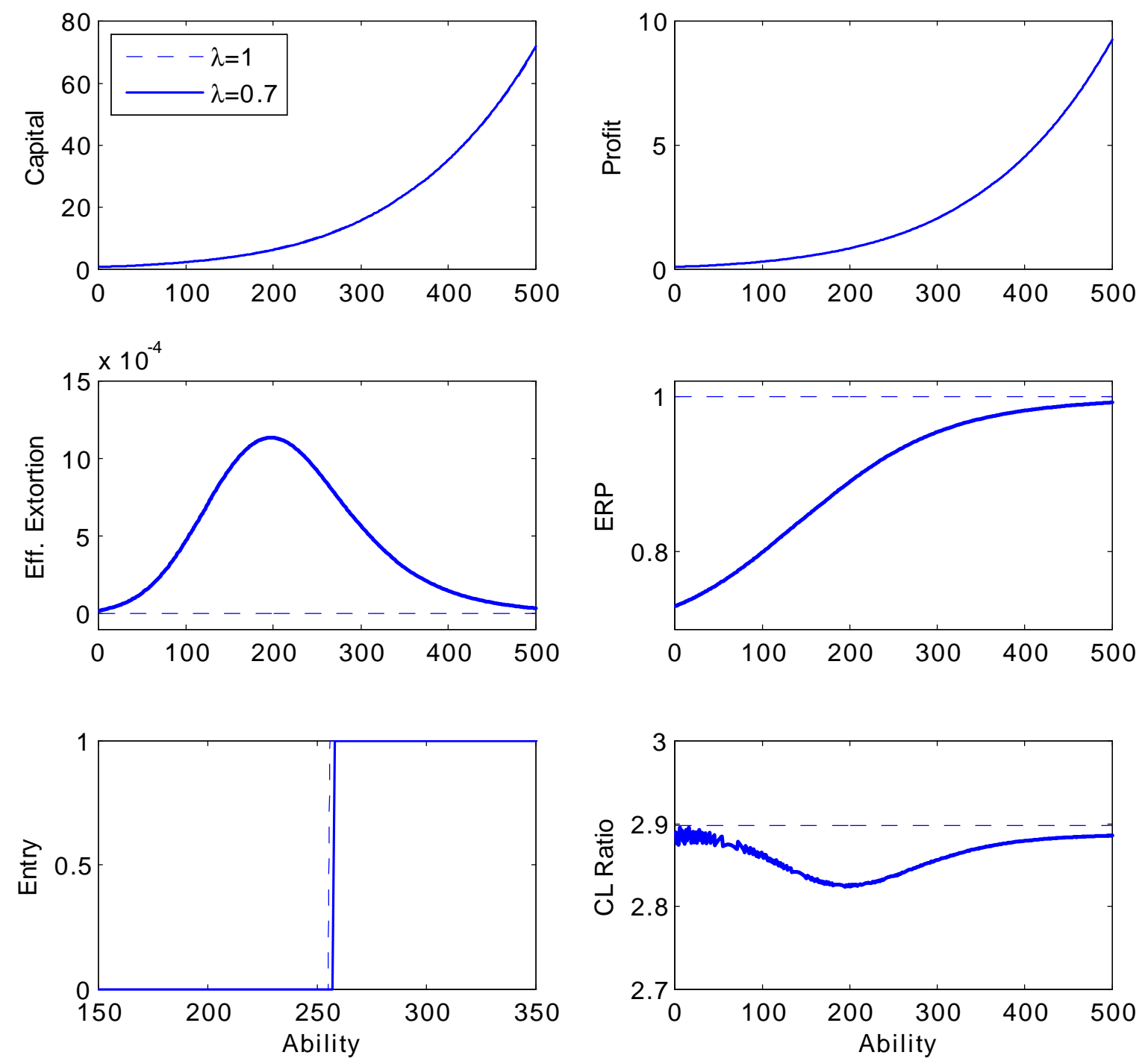

Figure 3: Effect of extortion across agents when $\lambda=0.7$. Note that the axis on the plot for entry (bottom left hand corner) is adjusted. 

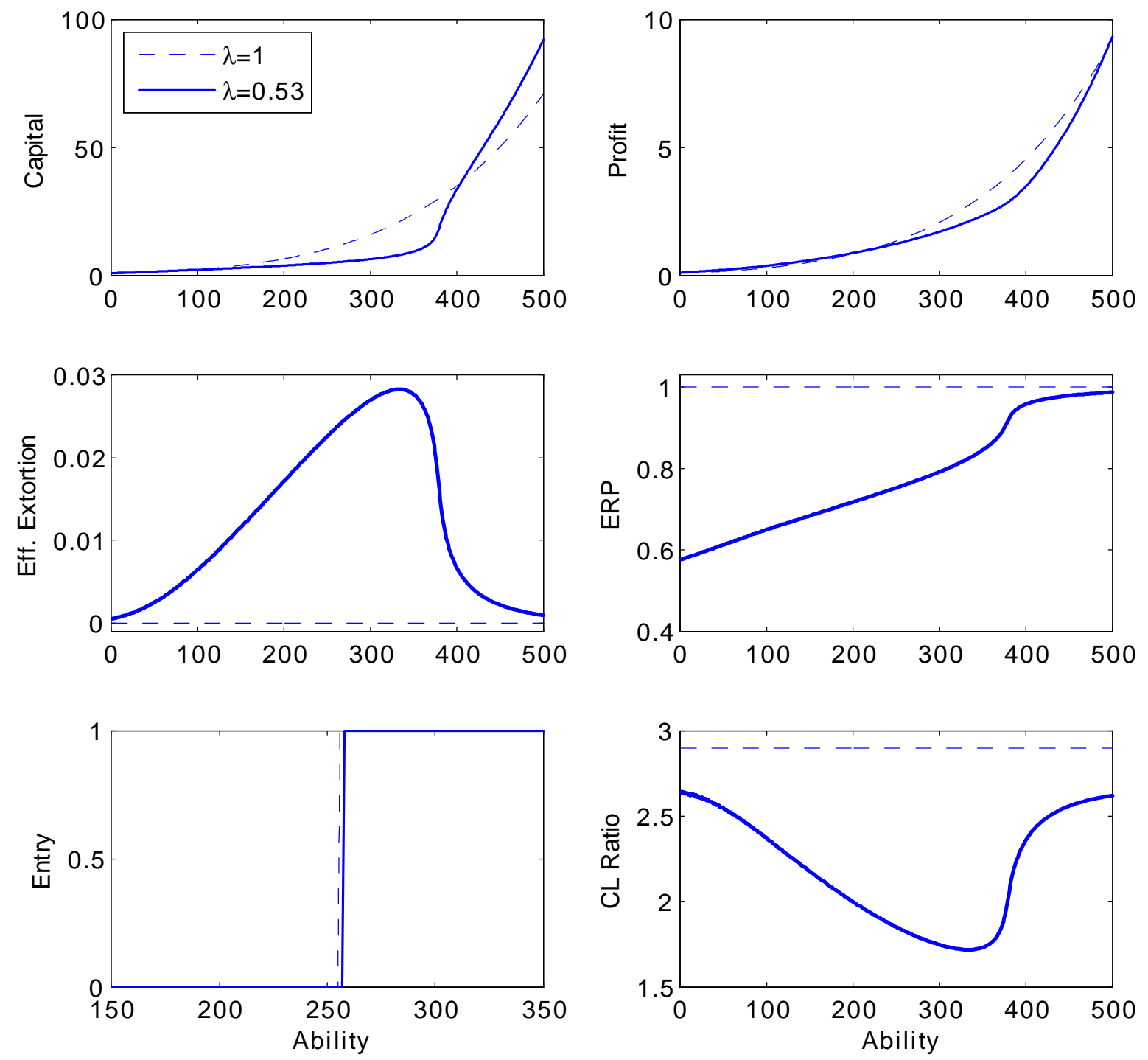

Figure 4: Effect of extortion across agents when $\lambda=0.53$. Note that the axis on the plot for entry (bottom left hand corner) is adjusted. 

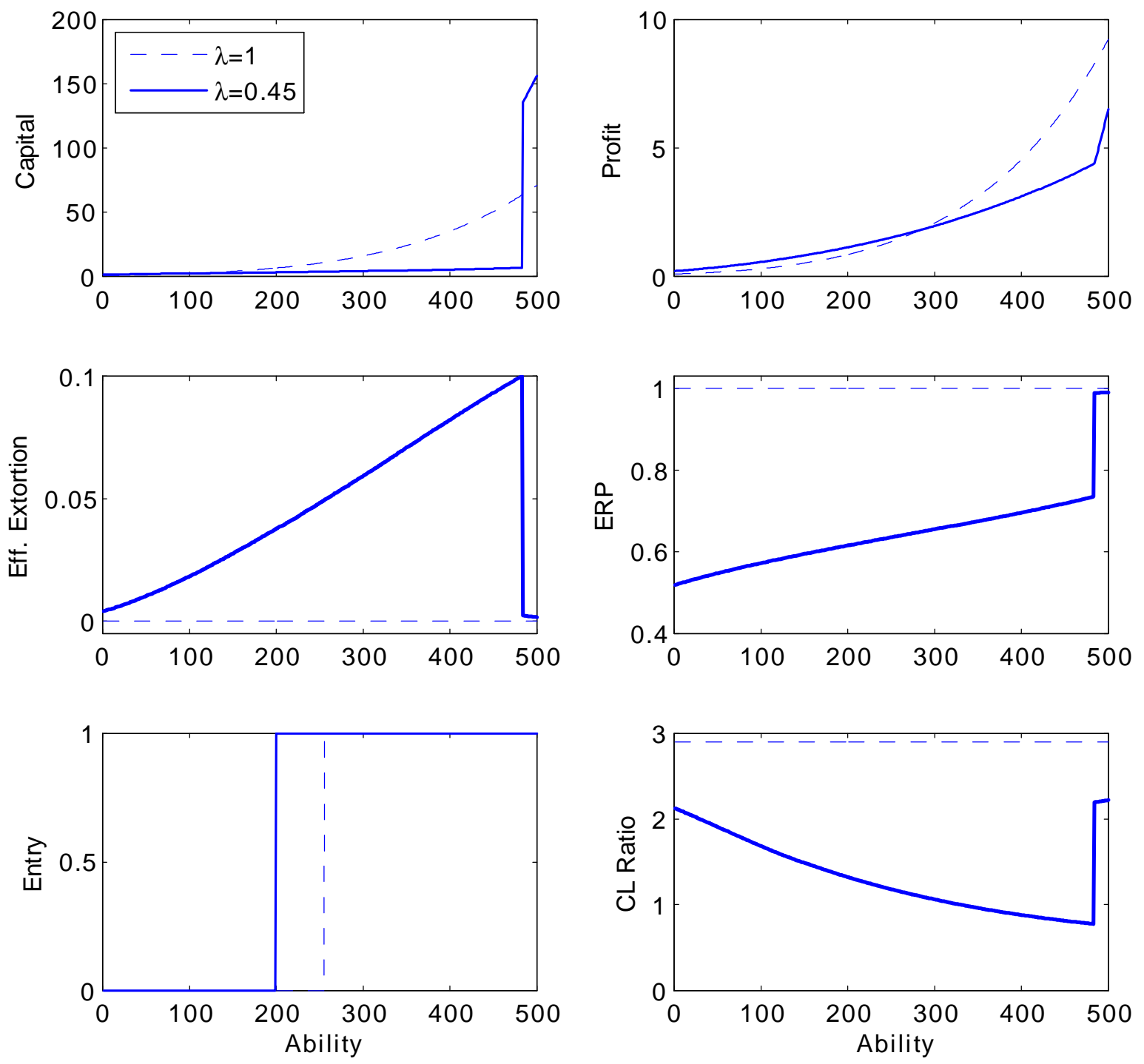

Figure 5: Effect of extortion across agents when $\lambda=0.45$. 


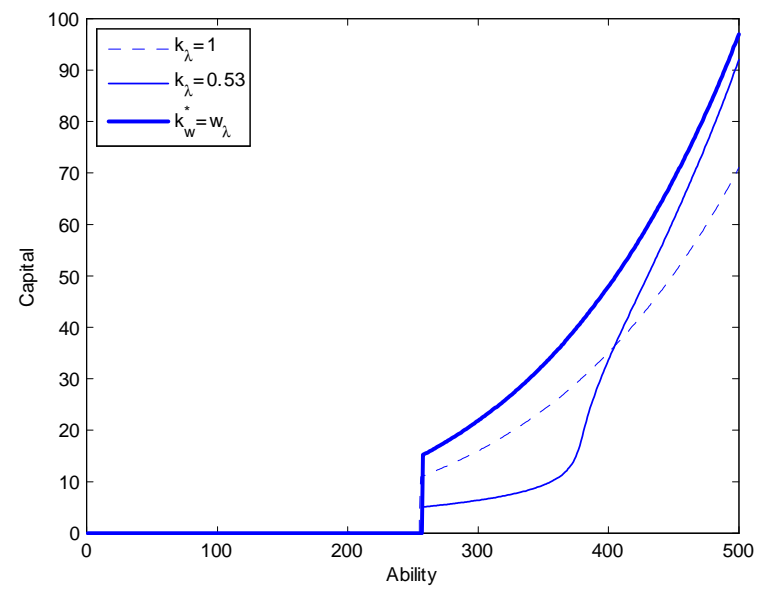

Figure 6: This Figure shows capital demand for agents who are entrepreneurs. The dashed line is capital demand in the first-best economy. The thin, solid line is capital demand by entrepreneurs when $\lambda=0.53$. The thick, solid line is the optimal capital demand, where $M P K=r$, given the prevailing wage when $\lambda=0.53$. Differences between the thin,solid and thick-solid line are $\triangle T F P_{m i s}$.
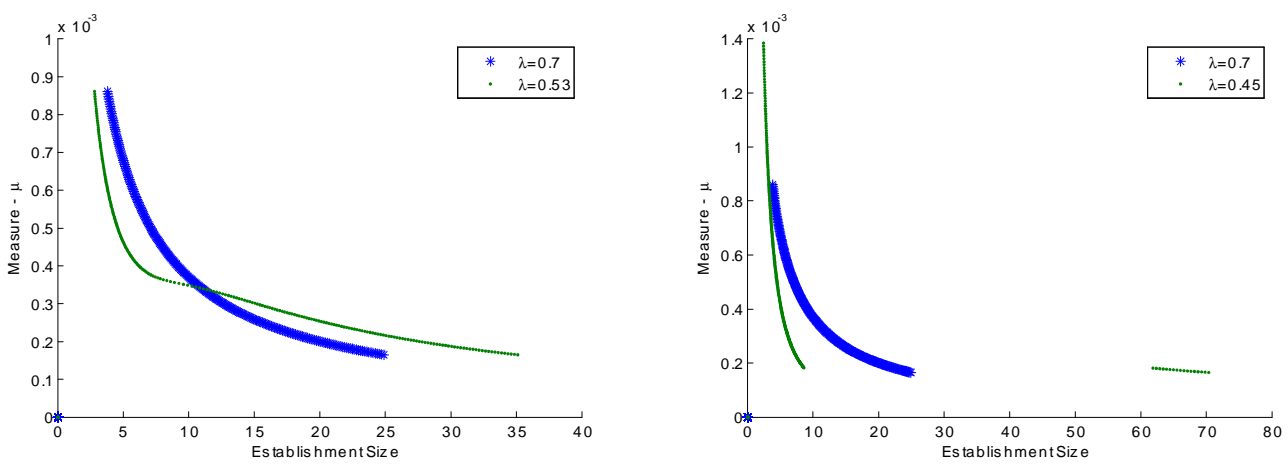

Figure 7: Distorted economies have a disproportionally larger amount of small establishments, as measured by labour demand. For the economy with $\lambda=0.45$, there is a missing middle in the distribution over establishment size. 


\section{Conclusion}

In this paper, I argue that when property rights are weak, extortion may be a key source of resource misallocation. A key prediction of the model is that while property rights are common across agents, extortion rates are an inverted ' $u$ ' shape in agent ability. The inverted ' $u$ ' shape arises because agent ability dictates how much protection they can afford. Given the varying rates of extortion how agents respond to extortion will differ. Low ability entrepreneurs may select out of entrepreneurship due to the high extortion rates they anticipate, while moderate ability entrepreneurs may continue to operate but at a smaller scale. High ability entrepreneurs buy significant protection, face little extortion and operate close to the optimal scale. Aggregate output and TFP losses due to extortion can be upwards of 30 and 10 percent, respectively, and are due to both selection and misallocation.

A large literature has emphasised that developing countries have an abundance of small establishments. Typical explanations involve policy distortions or financial frictions that limit the ability of establishments to expand. Extortion is another explanation for why developing countries may have so many small establishments. In an environment without financial frictions or policy distortions, the presence of extortion is sufficient to induce many establishments to remain small. This is similar to the empirical results by Johnson et al (2002) who find that weak property rights are more important to establishments remaining small, through lower investment, than access to finance. While access to finance is crucial for growth, a necessary condition is that property rights are secure. Entrepreneurs will seek financing for projects only if they are confident they can keep the entire returns from production.

This paper highlights how important property rights are for understanding resource misallocation. While property rights are exogenous in the model, they tend to be persistent over time, evolve gradually and require resources to sustain or improve it's quality. From the perspective of a benevolent government, taxes need to be imposed in order to fund the maintenance or improvement of property rights. A benevolent government therefore, from an efficiency perspective, faces a dilemma. Raising taxes to fund property rights can lead to TFP and output losses; the taxes on establishments can generate misallocation and selection effects. However, by sustaining or improving property rights, TFP and output losses that arise due to extortion can be mitigated as I have argued throughout this paper. It naturally follows to ask, from the view point of the government, if there is an optimal tax policy that funds property rights which is welfare improving. While an in depth analysis of such a question is beyond the scope of this paper I offer a few insights of what such a tax policy might do to agent incentives based on the model outlined in Section 2. 
Consider a proportional tax on profit/wage imposed on all agents in an economy where high (low) ability entrepreneurs face low (high) extortion rates; similar to the Polish economy in Figure 4. While sustained or improved property rights benefit all agents, the variation in the extortion rates they face imply that a proportional tax will benefit some agents more than others. For example, high ability entrepreneurs buy sufficient protection and face low extortion. A tax on profit can make purchasing high levels of protection no longer worthwhile and leave such entrepreneurs more susceptible to extortion. Conversely, low ability entrepreneurs buy little protection and face high extortion. Because their protection spending is low, a proportional tax on profit is likely to have little effect on their protection spending and so the gains in property rights will lower extortion and benefit them. Alternatively, one can consider a lump sum tax on all agents that standard economic theory suggests is non-distortionary. However, when extortion is present, even lump-sum taxes can be distortionary. Notwithstanding the effect a lump-sum tax can have on occupation choice decisions, consider the case of an entrepreneur who can just afford sufficient protection to thwart extortion and produce at the optimal capacity. Since protection expenditure acts as a fixed cost to the entrepreneur the imposition of a lump-sum cost can make buying protection no longer profitable. As a result, a forward looking entrepreneur who foresees high rates of extortion may optimally decide to produce below the optimal scale, which lowers output and TFP.

The effect a tax can have on an economy depends on the existing level of property rights and whether the government takes a short run or long run view to improving welfare. For countries with strong property rights, a tax can be welfare improving if it is offset by lower protection expenditure due to increased property rights. In countries that have weak property rights taxes may reduce output and TFP in the short run but could be potentially welfare improving in the long run. While taxes can induce firms to become smaller and lower production, in the long run sustained improvement in property rights can reduce extortion and enable establishments to gradually produce closer towards their optimal scale. Quantifying and evaluating each of these competing effects is left for future work. 


\section{References}

Acemoglu, D. 1995. Reward structures and the allocation of talent. European Economic Review, 39, 17-33.

Amaral, P. and E. Quintin. 2010. Limited Enforcement, Financial Intermediation and Economic Development: A Quantitative Analysis. International Economic Review,d 51(3), 785-811.

Barseghyan, L. and R. DiCecio. 2011. Entry costs, industry structure, and cross-country income and TFP differences. Journal of Economic Theory, 146, 1828-1851.

Bliss, C. and R. Di Tella. 1997. Does Competition Kill Corruption? The Journal of Political Economy, 105(5), 1001-1023.

Buera, F and Y. Shin. 2008. Financial Frictions and the Persistence of History: A Quantitative Explanation. mimeo.

Buera, F., J. Kaboski. and Y. Shin. 2011. Finance and Development: A Tale of Two Sectors. forthcoming in the American Economic Review.

Cagetti, M. and M. De Nardi. 2006. Entrepreneurship, Frictions and Wealth. The Journal of Political Economy, 114(5), 835-870.

Choi, J. and M. Thum. 2004. The economics of repeated extortion. RAND Journal of Economics, 35(2), 203-223.

Dal Bo, E., P. Dal Bo. and R. Di Tella. 2005. Reputation When Threats and Transfers Are Available. mimeo.

Dal Bo, E., P. Dal Bo. and R. Di Tella. 2006. Plata o Plomo?: Bribe and Punishment in a Theory of Political Influence. American Political Science Review, 100(1), 41-53.

D'Erasmo, P. and H. Moscoso Boedo. 2010. Financial Structure, Informality and Development. mimeo.

Gambetta, D. The Sicilian Mafia: The Business of Private Protection. Harvard University Press, 1996.

Gambetta, D. 2000. Mafia: The Price of Distrust. Trust: Making and Breaking Cooperative Relations, Chapter 10, 158-175. 
Greenwood, J., J Sanchez. and C. Wang. 2010. Quantifying the Impact of Financial Development on Economic Development. mimeo.

Grossman, H. and M. Kim. 1995. Swords or Plowshares? A Theory of the Security of Claims to Property. The Journal of Political Economy, 103(6), 1275-1288.

Grossman, H. and M. Kim. 1997. Predation, Efficiency, and Inequality. NBER Working Paper 6301.

Guner, N., G. Ventura. and Y. Xu. 2008. Macroeconomic Implications of Size Dependent Policies. Review of Economic Dynamics, 11(4), 721-744.

Hopenhayn, H. and R. Rogerson. 1993. Job Turnover and Policy Evaluation: A General Equilibrium Analysis. Journal of Political Economy, 101(5), 915-938.

Hsieh, C. and P. Klenow. 2009. Misallocation and Manufacturing TFP in China and India. Quarterly Journal of Economics, 124(4), 1403-1448.

Johnson, S., J. McMillan. and C. Woodruff. 2002. Property Rights and Finance. American Economic Review, 92(5), 1335-1356.

Konrad, K and S. Skaperdas. 1997. Credible threats in extortion. Journal of Economic Behavior $\&$ Organization, 33, 23-39.

Konrad, K. and S. Skaperdas. 1998. Extortion. Economica, 65, 461-477.

Lotspeich, R. 1997. An Economic Analysis of Extortion in Russia. MOCT-MOST, 7, 21-53.

Lucas, R. 1978. On the Size Distribution of Business Firms. The Bell Journal of Economics, $9(2), 508-523$.

Midrigan, V. and D. Xu. 2010. Finance and Misallocation: Evidence from Plant-Level Data. mimeo.

Moll, B. 2010. Productivity Losses from Financial Frictions: Can Self-Financing Undo Capital Misallocation. mimeo.

Moscoso Boedo, H. and T. Mukoyama. 2010. Evaluating the Effects of Entry Regulations and Firing Costs on International Income Differences. mimeo.

Murphy, K., A. Shleifer., and R. Vishny. 1993. Why Is Rent-Seeking So Costly to Growth?. American Economic Review, 83(2), 409-414. 
Olivella, V. 2010. Expropriation Risk and Aggregate Productivity with Heterogeneous Firms. mimeo.

Poschke, M. 2008. Who Becomes an Entrepreneur? Labor Market Prospects and Occupational Choice. IZA Discussion Paper No. 3816.

Poschke, M. 2009. Employment protection, firm selection, and growth. Journal of Monetary Economics, 56, 1074-1085.

Poschke, M. 2010. Entrepreneurs out of Necessity: A Snapshot. IZA Discussion Paper No. 4893.

Quadrini, V. 2000. Entrepreneurship, Saving and Social Mobility. Review of Economic Dynamics, 3, 1-40.

Restuccia, D and R. Rogerson. 2008. Policy Distortions and aggregate productivity with heterogeneous establishments. Review of Economic Dynamics, 11(4), 707-720.

Tybout, J. 2000. Manufacturing Firms in Developing Countries: How Well Do They Do, and Why? Journal of Economic Literature, 38(1), 11-44.

Volkov, V. 1999. Violent Entrepreneurship in Post-Communist Russia. Europe-Asia Studies, 51(5), 741-754. 


\section{Appendix}

Proposition 1: Subbing $e^{b r}(s)$ into equation (4) and maximizing with respect to $z$ yields,

$$
a z^{(\psi-\theta)(\rho-1)}+\Omega^{\rho-1} \lambda^{\rho} k^{\rho} z^{\theta}=\Omega^{\rho-1} \lambda^{\rho-1}(1-\lambda) k^{\rho} .
$$

A closed form solution for $z$ exists when $\theta=\frac{\psi(\rho-1)}{\rho} \cdot z^{*}(s) \leq \bar{z} \forall s$ when $a \geq 0$, which holds by assumption.

Proposition 2: Consider the case when $\tilde{\pi}\left(s_{1}\right)<\widetilde{\pi}\left(s_{2}\right)$, where $s_{1}>s_{2}$. Since $z^{*}(s)$ and $e^{*}(s)$ are functions of $k(s)$, and since $\pi(s)$ is increasing in ability, then from equation (3) and (4) an entrepreneur of type $s_{1}$ can be made better off - that is, $\widetilde{\pi}\left(s_{1}\right)>\widetilde{\pi}\left(s_{2}\right)$ - by choose capital and labour where $k\left(s_{1}\right)=k^{*}\left(s_{2}\right)$ and $n\left(s_{1}\right)=n^{*}\left(s_{2}\right)$. As such, $\tilde{\pi}\left(s_{1}\right)<\tilde{\pi}\left(s_{2}\right)$ is never an equilibrium outcome.

Proposition 3: If capital is increasing in productivity, it follows that $\frac{\partial z^{*}(s)}{\partial s} \geq 0$. Protection is increasing at a faster rate in agent ability when $\frac{\partial^{2} z^{*}(s)}{\partial s \partial s}>0$. This is positive when $(\rho-$ $\theta) a-\theta \Omega^{\rho-1} \lambda^{\rho} k(s)^{\rho}(1+\rho)>0$ or alternatively, when $\rho>\theta$ and $k(s)$ is small. $\frac{\partial^{2} z^{*}(s)}{\partial s \partial s}>0$ for all agents with ability $s<\widehat{s}$, where $\widehat{s}=k^{-1}\left(\left[\frac{(\rho-\theta) a}{\theta(1+\rho) \Omega^{\rho-1} \lambda^{\rho}}\right]^{\frac{1}{\rho}}\right)$.

Proposition 4: This requires examining how protection varies with property rights. When $\lambda \geq \frac{\rho-1}{\rho} \equiv \lambda^{c}, \frac{\partial z^{*}(s)}{\partial \lambda} \leq 0 \forall s$, implying protection and property rights are substitutes. When $\lambda<\lambda^{c}, \frac{\partial z^{*}(s)}{\partial \lambda} \leq 0$ only for agents with ability $s \geq k^{-1}\left(\left[\frac{a(\rho-\lambda \rho-1)}{\Omega^{\rho-1} \lambda^{\rho}}\right]^{\frac{1}{\rho}}\right)$.

Proposition 5: Subbing in for $z^{*}(s)$ and $e^{*}(s)$, an agent's effective rate of protection, as a function of capital, is given by $F(\lambda, z)=\frac{a \lambda+\Omega^{\rho-1} \lambda^{\rho} k(s)^{\rho}}{a+\Omega^{\rho-1} \lambda^{\rho} k(s)^{\rho}}$. This term is increasing in both property rights and ability.

Proposition 6: $\frac{\partial e^{*}(s)}{\partial s} \geq 0 \forall s \leq s_{x}$ and decreasing otherwise, where $s_{x} \equiv \frac{a}{(\rho-1) \Omega^{\rho-1} \lambda^{\rho}}$. Furthermore, $\frac{\partial s_{x}}{\partial \lambda}<0$.

Section 2.7, $\frac{\partial k^{*}(s)}{\partial s} \geq 0$. I use the profit function from Section 3.1 which depends only on capital since it is easier to work with. $\frac{\partial \widetilde{\pi}(s)}{\partial k(s)}=0$ when

$$
t s^{v}=r k^{x}+\frac{h k^{1+x}}{\left(a+\lambda^{2} k^{2}\right)^{2}},
$$


where $t=\frac{\alpha A}{1-\gamma}, v=\frac{1}{1-\gamma}, x=\frac{1-\alpha-\gamma}{1-\gamma}$ and $h=2 a(1-\lambda)^{2}$. It follows that $\frac{\partial k^{*}(s)}{\partial s} \geq 0$ if $\frac{\partial}{\partial k}\left(r k^{x}+\frac{h k^{1+x}}{\left(a+\lambda^{2} k^{2}\right)^{2}}\right) \geq 0$.

Section 3.1, re-writing of production function. $\pi(s)=\max _{n, k \geq 0} s k^{\alpha} n^{\gamma}-w n-r k$. Maximizing with respect to $n$ gives $n^{*}(s)=\left(\frac{\gamma s k^{\alpha}}{w}\right)^{\frac{1}{1-\gamma}}$. Subbing this back into $\pi(s)$ yields

$$
\pi(s)=\max _{k \geq 0} A s^{\frac{1}{1-\gamma}} k^{\frac{\alpha}{1-\gamma}}-r k
$$

For the aggregate production function when $\lambda=1$,

$$
\begin{aligned}
& k_{f b}^{*}(s)=\left(\frac{\alpha}{(1-\gamma) r}\right)^{\frac{1-\gamma}{1-\alpha-\gamma}} A^{\frac{1-\gamma}{1-\alpha-\gamma}} s^{\frac{1}{1-\alpha-\gamma}} \\
& y_{f b}^{*}(s)=\left(\frac{\alpha}{(1-\gamma) r}\right)^{\frac{\alpha}{1-\alpha-\gamma}} A^{\frac{1-\gamma}{1-\alpha-\gamma}} s^{\frac{1}{1-\alpha-\gamma}}
\end{aligned}
$$

let $h \equiv \frac{\alpha}{(1-\gamma) r}$. Then aggregate capital and output is given by

$$
\begin{aligned}
K & =\int_{S_{E} \in S} k^{*}(s) d \mu(s)=h^{\frac{1-\gamma}{1-\alpha-\gamma}} A^{\frac{1-\gamma}{1-\alpha-\gamma}} \int_{S_{E} \in S} s^{\frac{1}{1-\alpha-\gamma}} d \mu(s) \\
Y & =\int_{S_{E} \in S} y^{*}(s) d \mu(s)=h^{\frac{\alpha}{1-\alpha-\gamma}} A^{\frac{1-\gamma}{1-\alpha-\gamma}} \int_{S_{E} \in S} s^{\frac{1}{1-\alpha-\gamma}} d \mu(s)
\end{aligned}
$$

substituting out for $h$ in the aggregate capital equation and substituting into the aggregate output equation yields the aggregate output function and measured TFP in Section 3.1.

Decomposing TFP: Let $T F P_{f b}$ and $T F P_{\lambda}$ denote the TFP level for the economy with $\lambda=1$ and $\lambda<1$, respectively. The total change in TFP, between the undistorted and distorted economy, is $T F P_{f b}-T F P_{\lambda}$. The change in TFP if there is no misallocation is given by $T F P_{f b}-T F P_{\text {sel }}$, where $T F P_{\text {sel }}$ is TFP in the distorted economy where production is held at the optimal level $(M P K=r$ and $M P L=w)$. It follows that $T F P_{\text {mis }}=\left(T F P_{f b}-T F P_{\lambda}\right)-\left(T F P_{f b}-T F P_{s e l}\right)=T F P_{\text {sel }}-T F P_{\lambda} . \quad$ It follows that $\Delta T F P_{m i s}=\frac{T F P_{s e l}-T F P_{\lambda}}{T F P_{f b}-T F P_{\lambda}}$ and $\Delta T F P_{\text {sel }}=\frac{T F P_{f b}-T F P_{s e l}}{T F P_{f b}-T F P_{\lambda}}$, where $\Delta T F P_{\text {mis }}+\Delta T F P_{\text {sel }}=1$. 
Table 4 contains data related to extortion as reported in the Enterprise Survey by the World Bank. The second column documents the fraction of establishments that said other establishments made extortion payments. The third column reports the fraction of establishments that stated organized crime/mafia is a major or moderate obstacle to doing business. The fourth column is the average extortion payment conditional on the establishment reporting positive payments and the last column shows the dispersion in these payments, showing the tenth through 90 th percentile of the distribution.

Table 4: Extortion in Europe (Enterprise Survey 2005, World Bank)

\begin{tabular}{ccccc}
\hline \hline & $\begin{array}{c}\text { Faced Extortion } \\
\text { (\%of firms) }\end{array}$ & $\begin{array}{c}\text { Obs.to Operate } \\
\text { (\%of firms) }\end{array}$ & $\begin{array}{c}\text { Avg. Extortion Payment } \\
(\text { if }>0)\end{array}$ & $\begin{array}{c}10-90 \% \text { Percentile } \\
\text { (if }>0)\end{array}$ \\
\hline Armenia & $9 \%$ & $22 \%$ & 16.8 & {$[.43,13.5]$} \\
Bosnia & $14 \%$ & $38 \%$ & 138.6 & {$[2.3,606]$} \\
Bulgaria & $5 \%$ & $26 \%$ & 4.6 & {$[.27,8.9]$} \\
CzechRepublic & $3 \%$ & $27 \%$ & 22.6 & {$[2.4,52.2]$} \\
Hungary & $5 \%$ & $7 \%$ & 33.6 & {$[.51,104.2]$} \\
Kazakhstan & $6 \%$ & $16 \%$ & 17.4 & {$[.09,107.7]$} \\
Macedonia & $24 \%$ & $33 \%$ & 23 & {$[2.2,76.8]$} \\
Moldova & $21 \%$ & $25 \%$ & 20.5 & {$[.40,104]$} \\
Poland & $13 \%$ & $24 \%$ & 26.4 & {$[.72,62.7]$} \\
Romania & $12 \%$ & $24 \%$ & 24.1 & {$[.42,90]$} \\
Russia & $13 \%$ & $19 \%$ & 49.8 & {$[.40,132.9]$} \\
Slovakia & $26 \%$ & $6 \%$ & 54.2 & {$[.42,133.3]$} \\
Slovenia & $13 \%$ & $4 \%$ & 98 & {$[.30,11.1]$} \\
Tajikistan & $6 \%$ & $17 \%$ & 5.4 & {$[1.2,420]$} \\
Turkey & $23 \%$ & $32 \%$ & 103 & {$[.24,28.7]$} \\
Ukraine & $7 \%$ & $18 \%$ & 13 & \\
\hline \hline
\end{tabular}




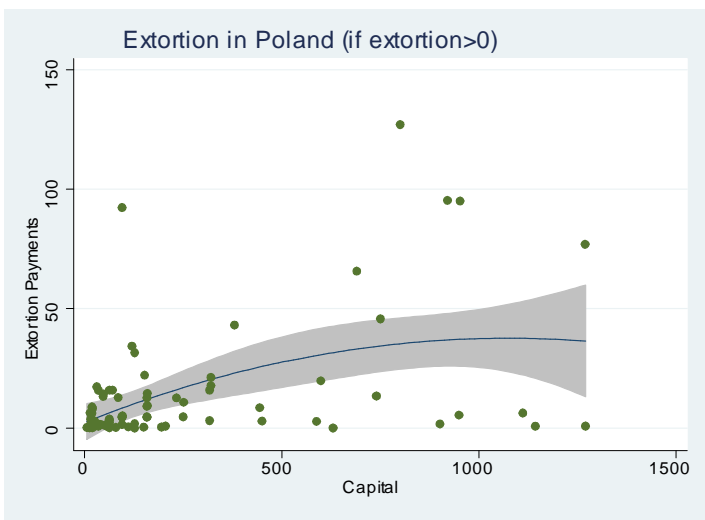

Figure 8: Figures (6 through 8) depict extortion payments by establishments to illegal organizations, conditional on extortion payments being greater than zero, in Poland, Romania and Turkey. Outlier data points are removed. Data source: Enterprise Survey from the World Bank.
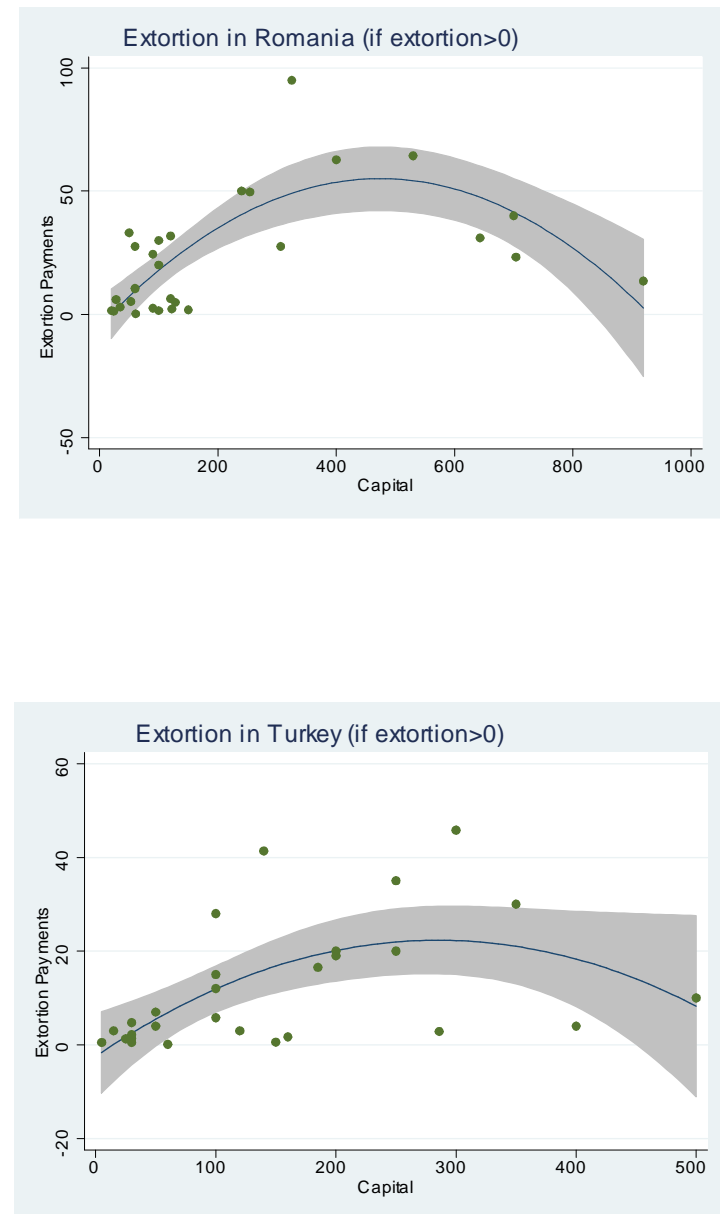


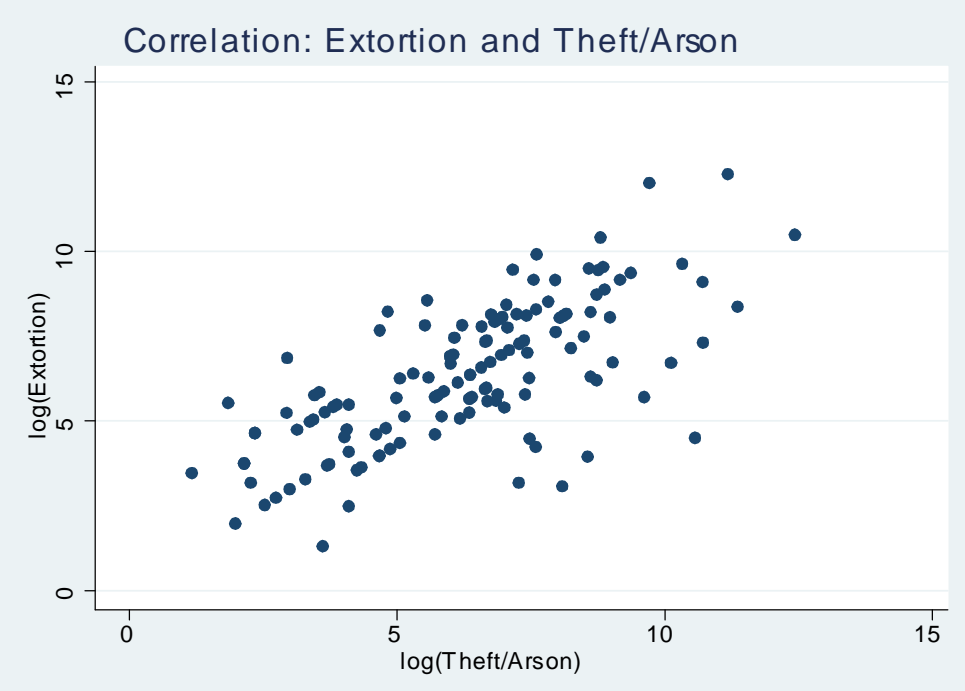

Figure 9: The scatter plot is between extortion and theft, in logs. The correlation is 0.7. Data points are from all countries that have both extortion and theft data (about 15 European countries). There are 135 observations.

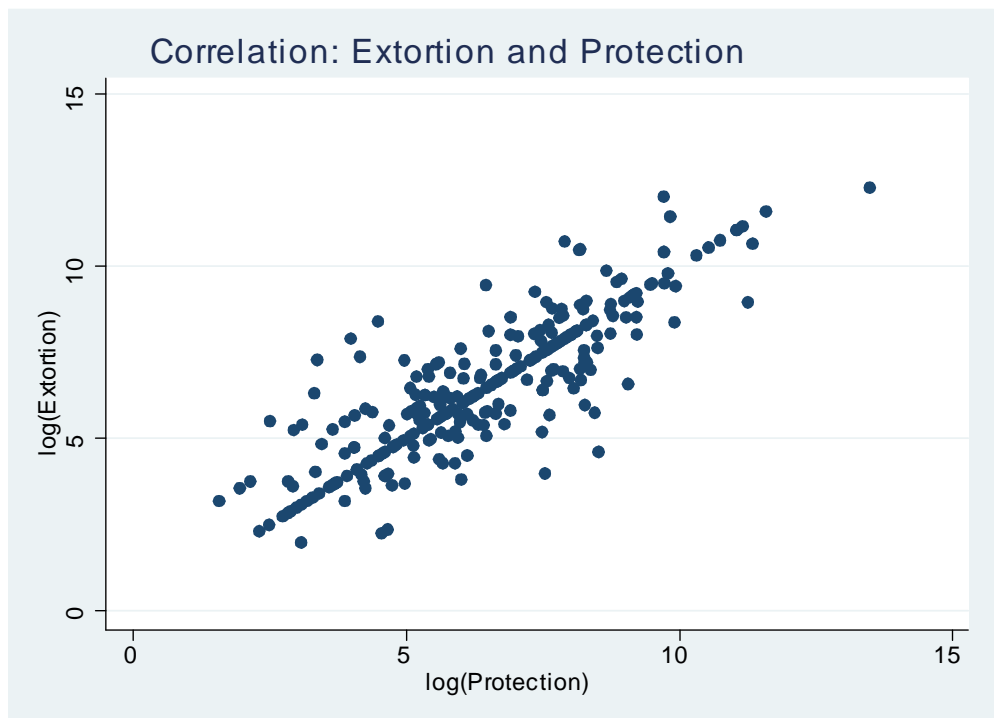

Figure 10: The scatter plot is between extortion and security expenditures (protection), in logs. The correlation is 0.86 . Data points are from all countries that have both extortion and protection data (about 15 European countries). There are 271 observations. 